International Journal of Soft Computing 7 (4): 157-163, 2012

ISSN: 1816-9503

(C) Medwell Journals, 2012

\title{
Information Access Based on Color in Children's Digital Library
}

\author{
Hairulliza Mohamad Judi, Tengku Siti Meriam Tengku Wook and Tai Ai Lee \\ Information Technology Study Centre, Faculty of Information Science and Technology, \\ Universiti Kebangsaan Malaysia, 43600 Bangi, Malaysia
}

\begin{abstract}
Children's digital library is a facility where children can find various resources to cater their information requirement and curious instinct. Among challenges in developing children's digital library involve designing information access in such a format that is suitable for them. This study aims to propose information access application based on color for children's digital library. This attribute is suitable for searching technique in the application since children may easily associate important information with colors. An application has been designed and developed to fulfill the requirement. The prototype has been tested among a group of children to test the reliability and usability of the system and the children's opinion on the library environment.
\end{abstract}

$\underline{\text { Key words: Searching technique, children, reliability, environment, library, Malaysia }}$

\section{INTRODUCTION}

Tremendous development in information and communication technology have resulted immense changes in conventional library with the emergence of digital library. Digital library is not just about a cluster of networked data base or digital information repository (Chowdhury and Chowdhury, 2003). Digital libraries offer facilities where huge parts of information sources are provided in such a format that they can be achieved through machine and computer technology. Users from various part of the world may access information in digital library with the availability of an efficient internet connection. Digital library has various form of information such as text, picture, video and audio.

Now a days, digital library users are no longer limited to adult, they include children. Children may take part in digital library to access information and consequently increase their knowledge by pressing computer keyboard. Children's digital libraries bring a lot of benefits to young generation. Children who used the International Children's Digital Library (ICDL) $>4$ years still valued their physical libraries as spaces for social interaction and reading; showed increased reading motivation and showed interest in exploring different cultures (Druin et al., 2007).

Graphic design of application interface plays important role in children's digital library. Graphic design provides a communication mechanism between children and computer. Poor graphic design contributed the most to the usability problem in Ilmu, a Malaysian web-based system that enables students including children to search and browse the bibliography section of books in libraries (Wook and Salim, 2006). Among the main issues of graphic design that contribute to the problem is the use of colors in the application. The use of color is very important in graphic design of children's digital library. Thus, this study embarks to propose an application that fulfills this issue.

The objectives of this study are as following: to develop information access application based on color for children's digital library and to evaluate information access in the proposed children's digital library system. Among the scope of this study involves the focus on books as they appear to fulfill and fit children's need and interest the most. The children's age need to be considered since this information may reflects their ability to access internet and to use the application. Thus, the children's digital library application is appropriate for children aged 7-11 years. Next, the function of information access is important, since searching and browsing is one of the most addressable issues by many researchers in children's digital library (Theng et al., 1999).

Children's digital library and graphic design: Books play an important role in children's lives. Books are among important resources to help children to understand who they are explore the world around them and develop their ability to be literate in the society (Grugeon and Gardner, 2000). Children represent the major internet user

Corresponding Author: Hairulliza Mohamad Judi, Information Technology Study Centre,

Faculty of Information Science and Technology, Universiti Kebangsaan Malaysia, 43600 Bangi, Malaysia 
group (Hutchinson et al., 2006). Accordingly, children's digital library plays an important role to meet their information requirement, curious instinct and entertainment needs.

Many of today's digital libraries are not designed for children (Druin, 2003). The available system offers interface design, layout and terminologies beyond children abilities to perform the library search smoothly. To design a good children's digital library, one requires the knowledge about children and their behavior what the library will be used for the context and the environment in which the library will be used and what is technically and logistically feasible (Theng et al., 2000). Suitable framework to design and implement September 27, 2012children's digital library including conditions for the library's good design and implementation has been proposed by Druin et al. (2003) and Wook et al. (2011).

Among the main problems in many digital libraries is regarding its outstanding graphic design as repositories of information (Theng et al., 2000). Graphic design refers to the appearance of the application's interface. Graphic design provides a communication mechanism between users and computer. Users' experience in digital libraries is considered passive and less engaging compared to the other web application. A good children's digital library design should consider element of fun, easy to use and empowerment that allow children to explore themselves both as readers and researchers.

Various studies have been conducted regarding graphic design in digital library. A study on the influence of digital library interface features on user perceptions shows that the interface features contributed to student's satisfaction (Lee et al., 2005). Realising that interface play important for a good children's digital library, a group of researchers have worked together with children to design new digital libraries for them (Druin, 2003). The environment and design features of children's digital library entail an engaging and successful learning experience for children using the facility.

Three issues are related to poor graphical design in Malaysian Information Retrieval System (IRS) for children: layout use of colors and aesthetics. Among the three, colors present unique characteristic for this specific user group, i.e., children have their own requirements and preferences over other user group. The use of color in children's digital library is vital as it helps in changing user's feeling or perception for system interface (Paal, 2004). The choice of colors must be balanced and consistent to avoid confusion among the users. Too much color effect will make the interface looks messy whereas too little color applied leads to a dull result.
A conceptual design that specifies children's requirements and preferences on graphic issues has been proposed by Wook and Salim (2007). The design involves identifying children's preferences on graphic design and generating design ideas using Participatory Design Method. Regarding color element, the results show that children prefer striking and various colors to be used, find blue presents a very interesting color and demand a clear background to be considered in the design.

Two children's digital libraries, namely International Children's Digital Library (ICDL) and story place were examined so that a comparison on their interface can be made. ICDL is an online library that specialize in children books from various languages. This library targets its users for children that aged between 3-13 years. This library is owned by International Children's Digital Library Foundation and is developed by College of Information Studies and Human-Computer Interaction Laboratory in University of Maryland, College Park. Children may search books in the collection based on the color of book cover, language, pagination, etc. This library supplies various search technique such as simple, keyword and advanced search to help children looking for a book of their liking.

Story Place is another digital library purposely to cater the needs of children. The library provides an attractive interface with rich of colors. This digital library is merged with education, jollification and activity functions. The establishment of this library took place in the year of 1999. The interface of Story Place is simple and involves less text. Based on the available children's digital libraries, important features in children's digital library interface are identified. These include minimal use of text, application of animation for interaction and inclusion of various colors and images. Information search should be simple and involves symbol to help them in the activity.

\section{MATERIALS AND METHODS}

The development of information search application for children's digital library follows System Development Life Cycle-SDLC methodology which comprises of five important phases which comprises of five important phases, namely planning, analysis, design, implementation and testing phases. It starts with identification of problem, objective and scope for systems development. Next, the current available systems were studied in detailed so that problems and solutions are identified, for example what users want in children's digital library. The design phase involves logical and physical designs of the system. In the implementation 
phase, system development takes place in which activities such as system coding, implementation and testing are undertaken.

In the final phase, various tests were carried out from time to time to ensure the system fits the function and free from programming error. The application was also evaluated by ten children aged from 7-11 years old. The feedbacks from this group of users were evaluated to examine the quality of the application. The instrument was modified from Hairulliza.

\section{RESULTS AND DISCUSSION}

This research aims to develop information access application based on color for children's digital library. The design of interface for this application considers important features in children's digital library, i.e., minimal use of text while apply various colors, graphics, fonts and drop down menu to attract children in using the system. The minimum use of multimedia element in the system is to avoid unnecessary weight of displaying the heavy content however, it retains some entertainment elements such as graphics and video. Some navigation elements are presented in the system to allow children explore the application as shown in Fig. 1.

The main interface of the system is shown in Fig. 2. It provides access to the main menu of the library and to the other links. Malay is used as the language in the system to fulfill the requirement of local children.
Figure 3 shows the procedure of registration as a new user for first timers. It requires basic information from children to become a member of the library. Only registered users are allowed to use the provided facility such as giving feedback and comments on children's digital library via the forum.

Figure 4 shows how the library collections are presented in a grid-view format in the library interface. The front page of the collection is presented as in the original copy. Important information regarding the collection are also presented including the title, researcher and publisher. The information search can be made based on colors. Children may pick any book to be read according to their preferred color. Once they click on any color, books with front page printed in the selected color will be listed. From the list, children will be able to explore the book of their liking.

Figure 5 shows forum facility in the proposed children's digital library. Registered users of this library may use the facility in the system. The forum allows them to leave their comment and feedback on the system. It is presented in a grid-view format. Other users may see the others comment and response back. The prototype is tested among a sample of users to examine its reliability and usability. Ten children are chosen to explore and evaluate the system. The instrument used for evaluation is shown in Table 1. It consists of three aspects in software quality, namely reliability, usability and software environment. The children were asked to give their

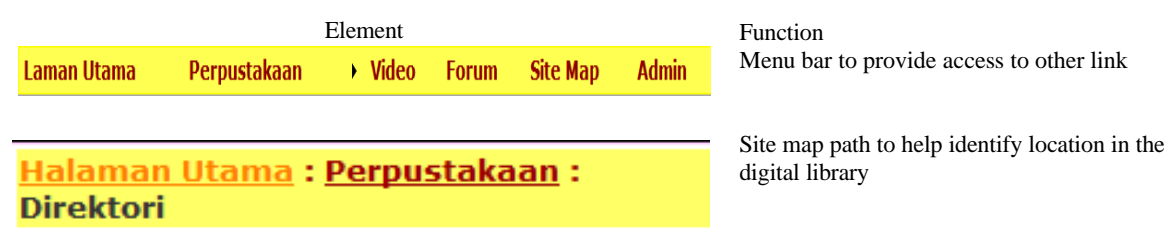

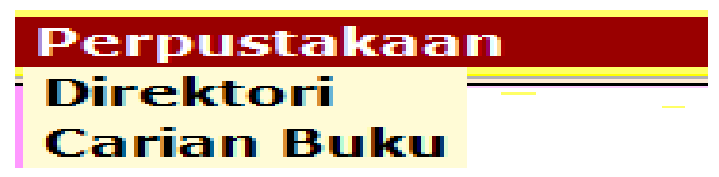

Drop down list for users to select various choices in the sub menu

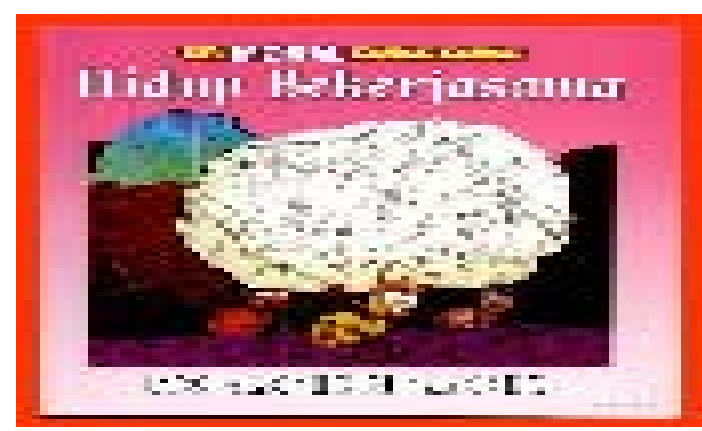

Image button to provide access to certain links

Fig. 1: Navigation element in children's digital library 
Int. J. Soft Comput., 7 (4): 157-163, 2012

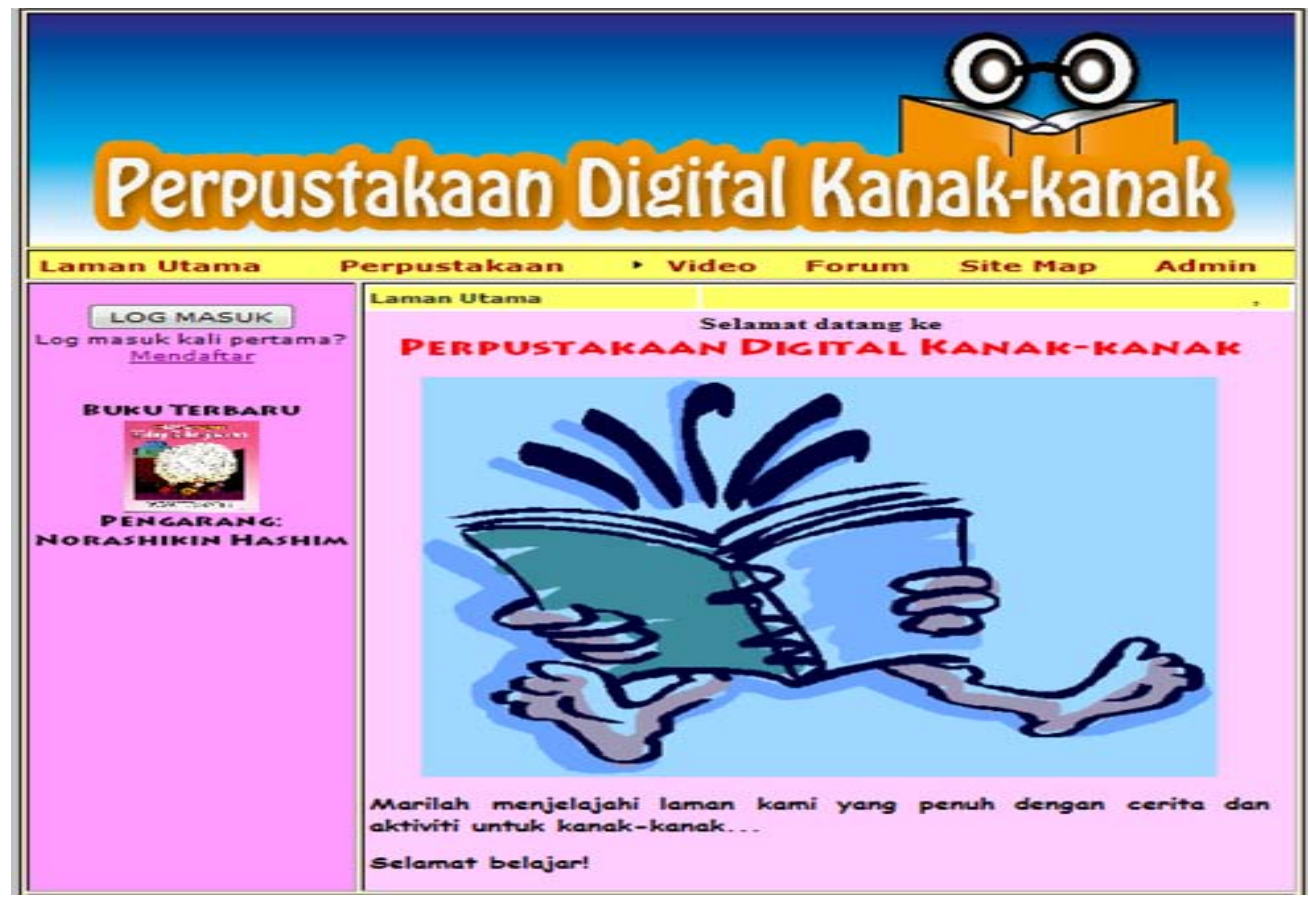

Fig. 2: Main interface of the proposed children's digital library

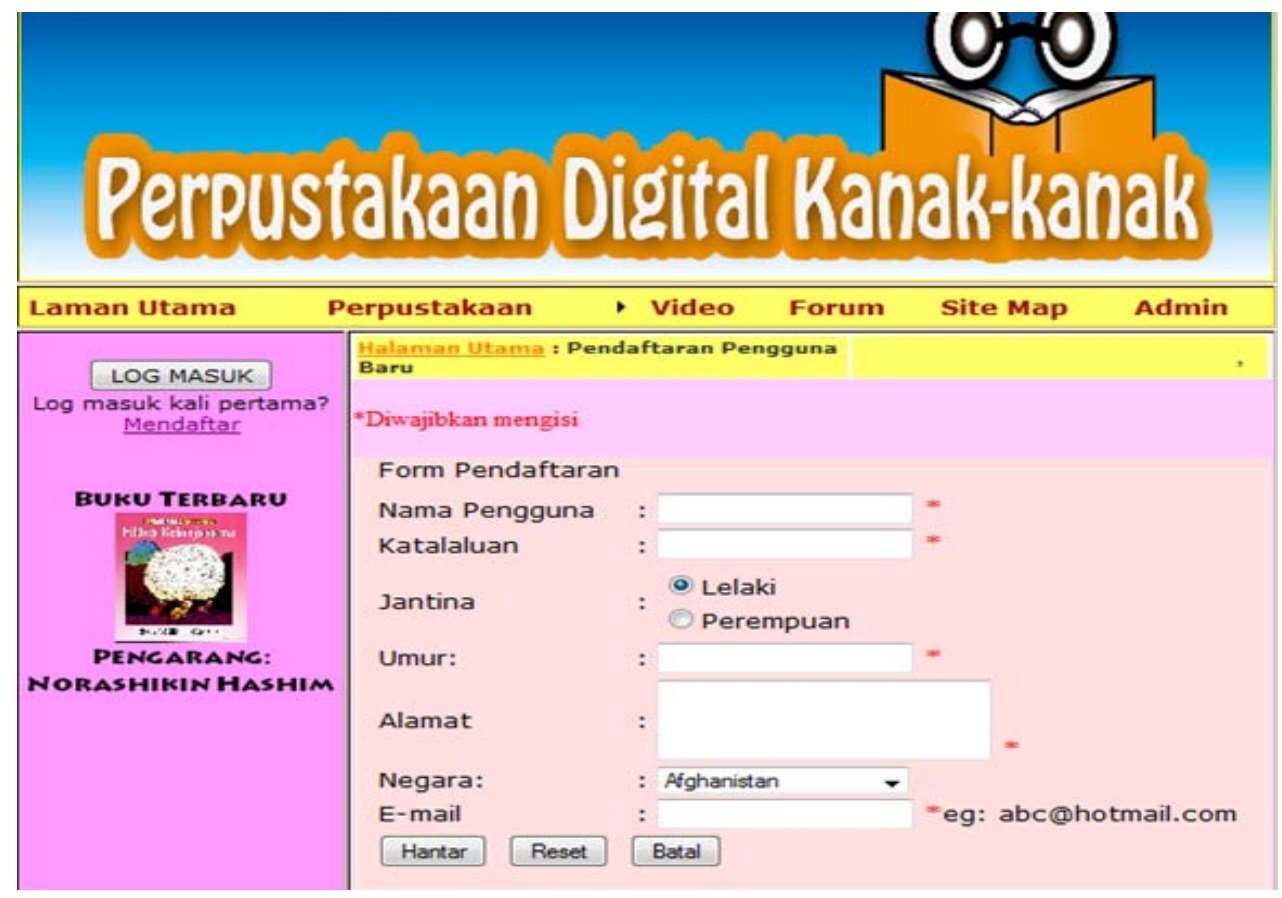

Fig. 3: New user registration

comment on the system after given enough time to access the application. The responses were analysed as shown in Table 1. The results show that there are elements in the proposed children's digital library that require improvement. These include providing sufficient output from the selected process. Table 2 presents the background information of the children. It shows the distribution of age and gender of participants. 


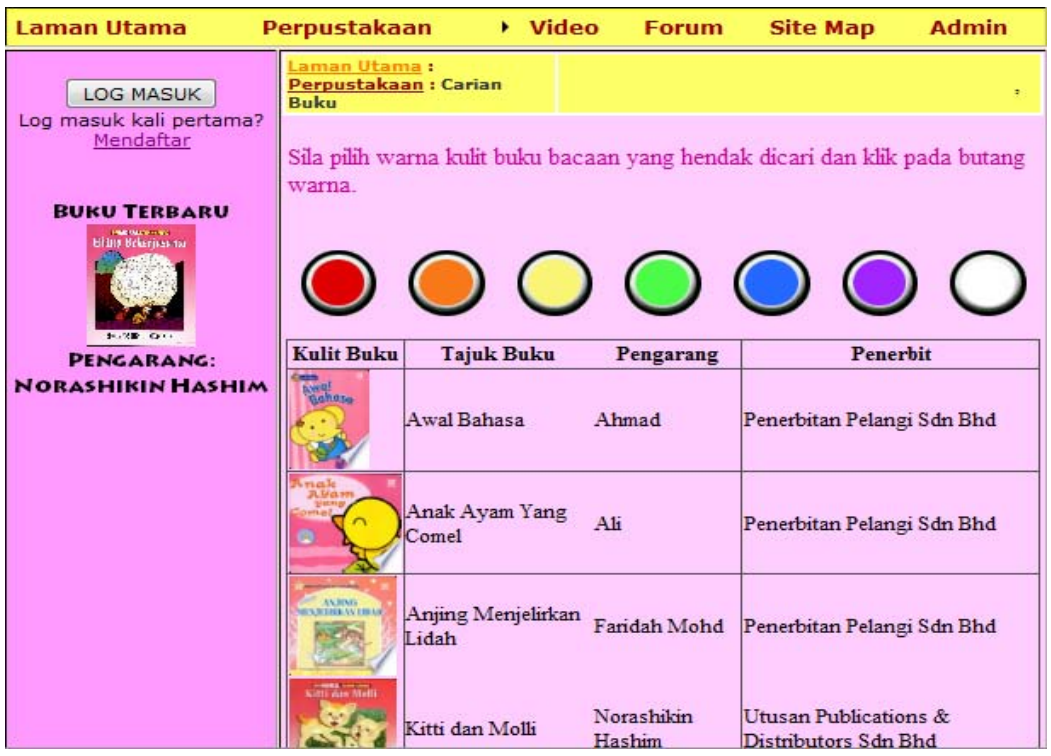

Fig. 4: Information access in the proposed children's digital library

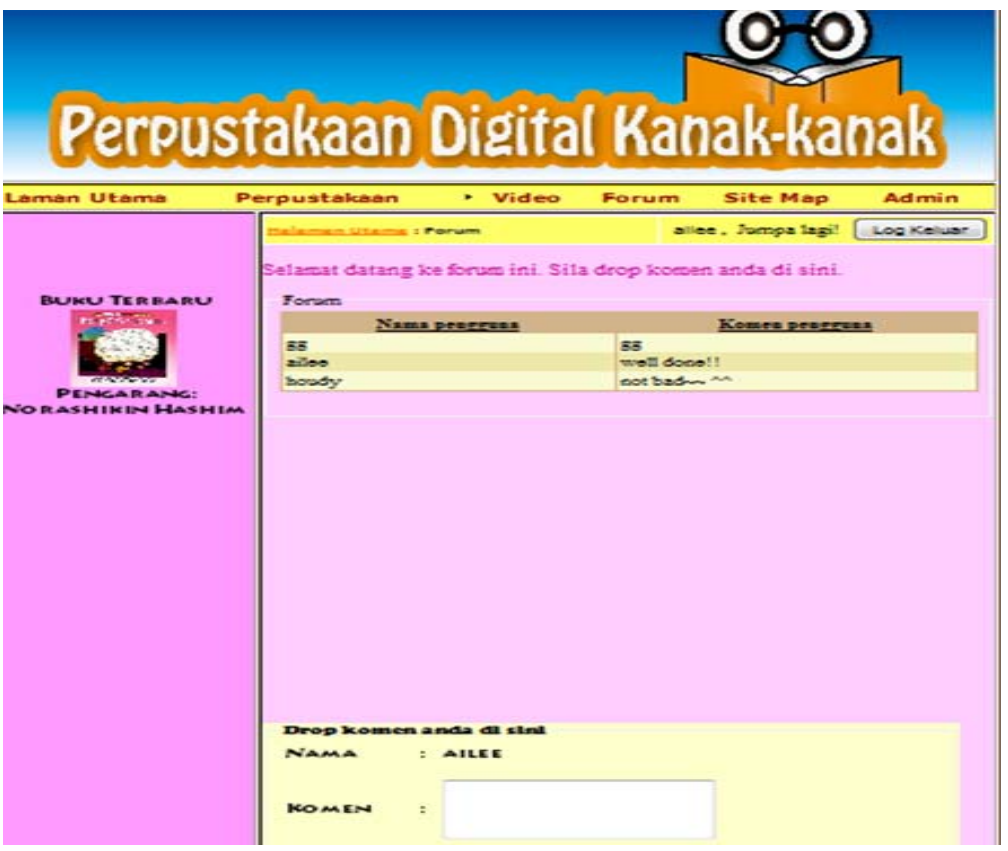

Fig. 5: Forum facility

This research has illustrated the possibility of accessing information in children's digital library based on colors. This attribute is suitable for searching technique in the application since children may easily associate important information with colors. An application has been designed and developed to fulfill the requirement of digital library for local users. The prototype has been used and tested among a group of children to test the reliability and usability of the system and their opinion on the library environment.
Similar to children in the rest of the world, children in Malaysia also depend on books to learn a lot about themselves and their environment (Grugeon and Gardner, 2000). Children's digital library plays an important role to meet their information requirement, curious instinct and entertainment. One way of doing that is by providing various suitable collection and reference material for children.

In comparison to traditional libraries, digital libraries offer various advantages. These include its ability to 
Int. J. Soft Comput., 7 (4): 157-163, 2012

Table 1: Evaluation of children's digital library application

\begin{tabular}{lcccr}
\hline Items & 1 (Not exist) & 2 (To a small level) & 3 (To a great level) & $4($ Completely) \\
\hline Reliability & - & - & - & - \\
Producing correct result & - & - & $2(20 \%)$ & $8(80 \%)$ \\
Ensuring correct input from user & - & - & - & $10(100 \%)$ \\
Presenting standardize output & - & - & - & $10(100 \%)$ \\
Easy to follow instruction & - & - & & $10(100 \%)$ \\
Usability & - & - & $8(80 \%)$ & \\
Functioning properly (not hang) & - & - & $7(70 \%)$ & $2(20 \%)$ \\
Adequate input & - & $5(50 \%)$ & $5(50 \%)$ & $3(30 \%)$ \\
Adequate output & - & - & - & - \\
Library environment & - & - & - & $10(100 \%)$ \\
User friendly & - & - & $2(20 \%)$ & $10(100 \%)$ \\
Easy information access & - & & $8(80 \%)$ \\
Interesting interface & &
\end{tabular}

Table 2: Background of participants

\begin{tabular}{llc}
\hline Factors & Category & Frequency \\
\hline Age & 7 & $2(20 \%)$ \\
& 8 & $1(10 \%)$ \\
& 9 & $4(40 \%)$ \\
& 10 & $2(20 \%)$ \\
Gender & 11 & $1(10 \%)$ \\
& Male & $4(40 \%)$ \\
& Female & $6(60 \%)$ \\
\hline
\end{tabular}

bring the libraries closer to users (Lee et al., 2005). Information are brought to users, either at home or work, making it more accessible and increases its usage. It has been proven that children who used digital library were exposed to large variety of books (Druin et al., 2007).

Children in Malaysia should also be given opportunity to access to digital libraries anticipated for them. The proposed children's digital library for local users emphasizes element of fun, easy to use and userfriendliness. The language used in the system is that the children are familiar with, i.e., Malay language. These elements are important to ensure that the instructions in the system are easy to be followed and the children enjoy the content of the books.

The reliability of the proposed application was evaluated using a few items. These include how the library is generating proper output and controlling input from users. The results show that the participants agree that the application is reliable. The usability of the application was evaluated to see it performs the deliberate function properly. Similarly, the results show agreement of this aspect except in providing sufficient output. Improvement should be made to include various responses from the system to the available process. The results also show that important features such as user friendliness, easy information access and interesting interface could be recognized from the system.

\section{CONCLUSION}

The proposed children's digital library highlights information access based on color. It is proposed here so that future attempt could be taken by researchers and practitioners to develop a children's digital library for the usage of children. Collaboration between researchers, practitioners and children are required to design new digital libraries for children (Druin, 2003; Wook et al., 2011).

\section{REFERENCES}

Chowdhury, G.G. and S. Chowdhury, 2003. Introduction to Digital Libraries. Facet Publisher, London, UK., ISBN: 9781856044653 , Pages: 359.

Druin, A., 2003. What children can teach us: Developing digital libraries for children with children. http:/hcil.cs.umd.edu/trs/2003-39/2003-39.pdf.

Druin, A., A. Weeks, S. Massey and B.B. Bederson, 2007. Children's interests and concerns when using the international children's digital library: A four-country case study. Proceedings of the 7th ACM/IEEE-CS Joint Conference on Digital Libraries, June 17-22, 2007, Vancouver, Canada, pp: 167-176.

Druin, A., G. Revelle, B.B. Bederson, J.P. Hourcade, A. Farber, J. Lee and D. Campbell, 2003. A collaborative digital library for children. J. Comput. Assisted Learn., 19: 239-248.

Grugeon, E. and P. Gardner, 2000. The Art of Storytelling for Teachers and Pupils: Using Stories to Develop Literacy in Primary Classrooms. David Fulton Publisher, London, UK., ISBN: 9781853466175 , Pages: 128 .

Hutchinson, H.B., B.B. Bederson and A. Druin, 2006. The evolution of the international children's digital library searching and browsing interface. Proceedings of the Conference on Interaction Design and Children, June 7-9, 2006, Tampere, Finland, pp: 105-112.

Lee, G.T., N. Dahlan, T. Ramayah, N. Karia and M.H. Abu Hassan Asaari, 2005. Impact of interface characteristics on digital libraries usage. Malaysian Online J. Instructional Technol., 2: 1-9. 
Paal, K., 2004. Graphic design using color. http://ezinearticles.com/?Graphic-Design-Using-Color \& id=16.

Theng, Y.L., E. Duncker, N. Mohd-Nasir, G. Buchanan and H. Thimbleby, 1999. Design guidelines and user-centred digital libraries. Proceedings of the 3rd European Conference on Research and Advanced Technology for Digital Libraries, September 22-24, 1999, Paris, France, pp: 852-853.

Theng, Y.L., N. Mohd-Nasir, H. Thimbleby, G. Buchanan and M. Jones, 2000. Designing a children's digital library with and for children. Proceedings of the 5th ACM Conference on Digital Libraries, June 2-7, 2000, San Antonio, TX., USA., pp: 266-267.
Wook, T.S.M.T. and S.S. Salim, 2006. User testing of children's WebOPAC: A malaysian experience. Proceedings of the 7th Asia-Pacific Conference on Computer Human Interaction, October 11-14, 2006, Taiwan.

Wook, T.S.M.T. and S.S. Salim, 2007. A conceptual design for children's WebOPAC interface: Graphic design issues. Proceedings of the Symposium on Human Interface Part II, July 22-27, 2007, Beijing, China, pp: 785-791.

Wook, T.S.M.T., N. Sahari, S.F.M. Noor, N.A.H.M. Zin and A. Jaafar, 2011. Framework of visual interface for children's digital library. Proceedings of the International Conference on Electrical Engineering and Informatics, July 17-19, 2011, Bandung, Indonesia, pp: 1-4. 